The Spectrum of

\title{
NREL Helps Cool the Power Electronics in Electric Vehicles
}

Researchers at the National Renewable Energy Laboratory (NREL) are developing and demonstrating innovative heat-transfer technologies for cooling power electronics devices in hybrid and electric vehicles. In collaboration with $3 \mathrm{M}$ and Wolverine Tube, Inc., NREL is using surface enhancements to dissipate heat more effectively, permitting a reduction in the size of power electronic systems and potentially reducing the overall costs of electric vehicles.

Widespread use of advanced electric-drive vehicles - including electric vehicles (EVs) and hybrid electric vehicles (HEVs) — could revolutionize transportation and dramatically reduce U.S. oil consumption. Improving the cost and performance of these vehicles' electric-drive systems is key to their widespread acceptance in the marketplace. That is why NREL researchers are working to develop thermal management technologies for advanced power electronics that increase power density while lowering costs.

Effective temperature management is essential in all electronic devices. As temperatures rise, the efficiency, reliability, and life spans of these devices drop, and the power electronics inside HEVs and EVs are no exception. A key component is the inverter, which converts direct-current power from the batteries into alternating-current power for electric motors. Inverters depend on insulated-gate bipolar transistors (IGBTs), which are fast-switching solid-state electronics that must stay below $175^{\circ} \mathrm{C}\left(347^{\circ} \mathrm{F}\right)$ to function properly. In addition to keeping these components cool, efficient heat dissipation enables fewer, smaller devices for the same amount of power, resulting in cost savings.

"We want to operate these devices at as high a power level as we can," says Sreekant Narumanchi, a researcher in NREL's Advanced Power Electronics Laboratory. "With appropriate cooling, we can deliver the same power to the motor while reducing the size, weight, and cost of the inverter."

In many of today's EVs and HEVs, inverters are cooled by a liquid that is pumped through a dedicated portion of the vehicle's radiator, releasing its heat to the surrounding air. NREL is improving

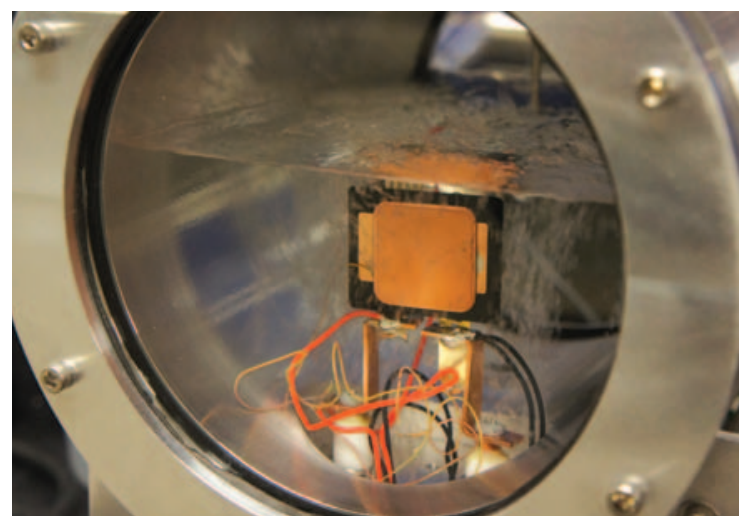

NREL is developing improved cooling systems for the power electronics devices in hybrid and electric vehicles. Researchers are enhancing the surfaces of these devices with microporous coatings to accelerate the transfer of heat to the surrounding coolant. This two-phase system has demonstrated a fivefold improvement in heat transfer relative to traditional systems, potentially yielding a system with a lower weight, volume, and cost.

Photo by Gilbert Moreno, NREL/PIX 18927
Clean Energy Innovation

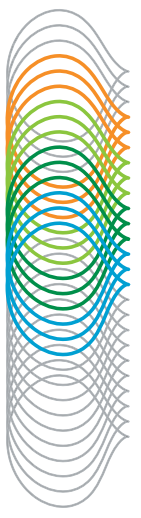

Fundamental Science

Market-Relevant Research

Systems Integration

Testing and Validation

Commercialization

Deployment

Through deep technical expertise and an unmatched breadth of capabilities, NREL leads an integrated approach across the spectrum of renewable energy innovation. From scientific discovery to accelerating market deployment, NREL works in partnership with private industry to drive the transformation of our nation's energy systems.

This case study illustrates NREL's contributions in Market-Relevant Research through Testing and Validation.
NREL is a national laboratory of the U.S. Department of Energy, Office of Energy Efficiency and Renewable Energy, operated by the Alliance for Sustainable Energy, LLC. 
that process by employing advanced surface enhancement technologies in configurations that have not been used before in automotive power electronics systems.

\section{Enhanced Surfaces in a Two-Phase Cooling System}

Using a microporous coating from $3 \mathrm{M}$ and a process called immersion boiling or pool boiling, NREL researchers have demonstrated significant increases in heat transfer rates from the IGBT devices to the coolant. The $3 \mathrm{M}$ coating contains millions of microscopic pores, which increase the surface area and number of nucleation sites and accelerate the bubble formation process to promote boiling.

The rapid motion of the gaseous bubbles, along with energy required for converting liquid to vapor, efficiently draws heat from the IGBT devices. The system's thermal resistance is more than $50 \%$ lower than that of a traditional single-phase waterethylene glycol cooling system. Researchers estimate that the system's impressive thermal performance could cut IGBT power module costs by more than half. As added benefits, the immersion boiling system might eliminate coolant pumps and the associated parasitic power requirements, while utilizing the existing refrigerant in the vehicle air-conditioning system, creating additional cost savings.

"Using pool boiling to cool power electronics is still not accepted in industry," says Narumanchi, "but the heat transfer results of immersion boiling on the microporous coating are quite dramatic and provide a strong case for more widespread use of this approach."

\section{Microdeformed Surfaces in a Single-Phase Cooling System}

Narumanchi and his colleagues have also developed a single-phase cooling system that uses a surface enhancement called MicroCoo ${ }^{\mathrm{TM}}$, developed by Wolverine Tube, Inc. In this liquid-only system, 1.5-mm-diameter jets direct liquid coolant onto the enhanced surface. These microdeformed surfaces increase the total surface area and reduce the thermal resistance between the solid surface and the liquid, thereby accelerating heat transfer. Using this configuration, researchers have achieved improvements in heat-transfer rates of up to 100\% compared with techniques that do not use enhanced surfaces.

"While single-phase liquid cooling in conventional channel flow configurations is widely employed in commercial HEV power electronics heat exchangers, our configuration of single-phase jets used in conjunction with enhanced surfaces is novel," says Narumanchi. "We are covering new ground and proving to our partners in industry that significant gains are well within reach."

\section{Supporting Long-Term Goals for Advanced Vehicles}

The U.S. Department of Energy's (DOE) Vehicle Technologies Program has set targets to reduce the cost of power electronics and electric motors from $\$ 30$ per kilowatt to $\$ 8$ per kilowatt by 2020. NREL's pioneering work in thermal management for power electronics provides critical support to DOE goals and will ultimately help accelerate the deployment of clean and efficient vehicles.

"We have demonstrated vastly improved heat transfer rates," says Narumanchi. "Now we're turning our attention to the challenges of increasing reliability, reducing complexity, and then demonstrating these configurations in practical inverters. Our hope is that by 2015 , the automotive industry will be able to put these configurations to use in commercial vehicles."

\section{Enhanced Surfaces Improve Heat Transfer in Power Electronics Devices}

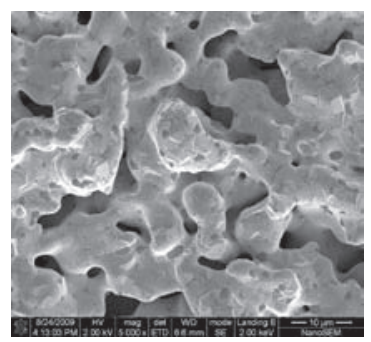

NREL researchers have applied microporous surface coatings to automotive power electronics devices, achieving significant improvements in thermal management. The coating's microscopic pores, shown here in a scanning electron microscrope image, increase surface area and accelerate bubble formation, drawing heat away from the device. NREL/PIX 19353
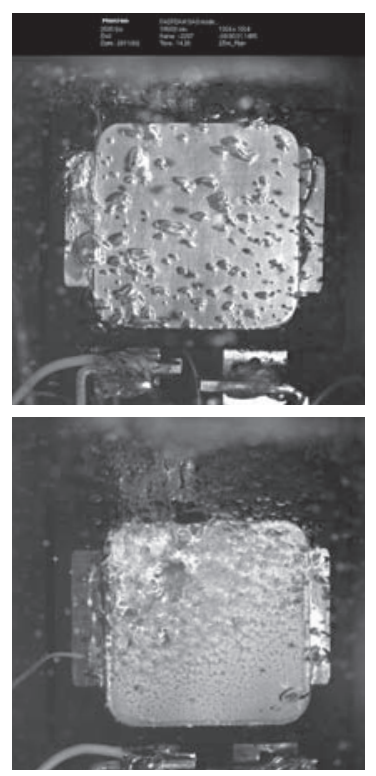

Two-phase cooling of an automotive power electronics module without (top) and with (bottom) the use of a microporous coating. Top: NREL/PIX 19352, Bottom: NREL/PIX 19351

\section{National Renewable Energy Laboratory}

1617 Cole Boulevard

Golden, Colorado 80401-3305

303-275-3000 • www.nrel.gov

NREL is a national laboratory of the U.S. Department of Energy, Office of Energy Efficiency and Renewable Energy, operated by the Alliance for Sustainable Energy, LLC.

NREL/FS-6A42-50989 • July 2011

Printed with a renewable-source ink on paper containing at least $50 \%$ wastepaper, including $10 \%$ post consumer waste. 